Cite this article as: BMJ, doi:10.1136/bmj.39167.439792.55 (published 27 April 2007)

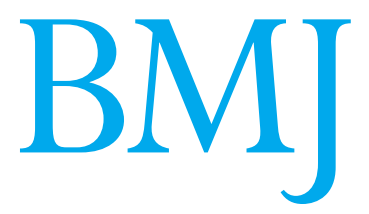

RESEARCH

\title{
Social inequalities in self reported health in early old age: follow-up of prospective cohort study
}

\author{
Tarani Chandola, senior lecturer, ${ }^{1}$ Jane Ferrie, senior research fellow, ${ }^{1}$ Amanda Sacker, principal research \\ fellow, ${ }^{1}$ Michael Marmot professor ${ }^{1}$
}

International Institute for Society and Health, Department of Epidemiology and Public Health University College London, London SE11 4LD

Correspondence to: T Chandola t.chandola@ucl.ac.uk

doi: 10.1136/bmj.39167.439792.55

\section{ABSTRACT}

Objective To describe differences in trajectories of self reported health in an ageing cohort according to occupational grade.

Design Prospective cohort study of office based British civil servants (1985-2004).

Participants 10308 men and women aged 35-55 at baseline, employed in 20 London civil service departments (the Whitehall II study); follow-up was an average of 18 years.

Main outcome measures Physical component and mental component scores on SR-36 measured on five occasions. Results Physical health deteriorated more rapidly with age among men and women from the lower occupational grades. The average gap in physical component scores between a high and low grade civil servant at age 56 was 1.60 and this gap increased by 1 over 20 years. The average physical health of a 70 year old man or woman who was in a high grade position was similar to the physical health of a person from a low grade around eight years younger. In mid-life, this gap was only 4.5 years. Although mental health improved with age, the rate of improvement is slower for men and women in the lower grades.

Conclusions Social inequalities in self reported health increase in early old age. People from lower occupational grades age faster in terms of a quicker deterioration in physical health compared with people from higher grades. This widening gap suggests that health inequalities will become an increasingly important public health issue, especially as the population ages.

\section{INTRODUCTION}

Health in general tends to deteriorate as people get older. There may, however, be social inequalities in the trajectories of age related health decline. Cross sectional evidence from the English population suggests that the prevalence of ill health in people aged 50-59 from routine and manual social classes is greater than among older people from professional and managerial social classes. ${ }^{1}$ This could mean people from disadvantaged social classes age faster in terms of declining health compared with professional classes. ${ }^{1}$ Longitudinal analyses would be needed to disentangle the effects of age, period, and cohort that are conflated in such cross sectional data.
If people from disadvantaged social classes age faster in terms of declining health, this would result in widening health inequalities in later life. Reductions in inequalities in health are an important policy target in Britain. With an ageing population, the question of whether socioeconomic differences in health persist, increase, or decrease at older ages becomes increasingly salient.

While absolute differences in health between socioeconomic groups increase at older ages, ${ }^{2}$ most cross sectional studies show converging relative health inequalities among the oldest age groups. ${ }^{34}$ Evidence from longitudinal studies is conflicting, however, with some studies showing decreasing health inequalities with age ${ }^{25-7}$ while others find persisting or even widening inequalities in health in later life. ${ }^{8-10}$ Some of the discrepancies might arise from the different contexts of these studies, such as differing populations, study periods, age groups, and health measures. Most longitudinal analyses examined mortality as the outcome, ${ }^{26710}$ a few examined morbidity ${ }^{589}$ and only one separated out age and period or cohort effects. ${ }^{11}$ Distinguishing between these effects is especially important in the context of health and ageing. ${ }^{12}$ In particular, converging or diverging inequalities in health with ageing may result from period effects such as retirement, which leads to changed socioeconomic circumstances. Sacker et al suggest that analytical approaches such as growth curve modelling can be used to separate the effects of ageing and period or cohort. ${ }^{11}$ Furthermore, these models enable socioeconomic position to be specified as an exposure that varies as people age.

Widening health inequalities in early old age may be particularly marked for some groups such as women and retired people. Earlier evidence suggested that women tend to report greater morbidity and poorer functioning than men, ${ }^{13}$ and this sex difference may increase as they age. ${ }^{14}$ In addition, women from disadvantaged classes may experience greater health declines with age than men from a similar class. As people from disadvantaged social classes are more likely to retire for health reasons, ${ }^{15}$ retirement may also exacerbate health inequalities if their health continues to decline more quickly in retirement and result in widening health inequalities in early old age. 
We examined whether people in lower occupational classes age faster in terms of a quicker decline in self reported health compared with those belonging to more advantaged classes and whether the effect of occupational class on these trajectories varies by sex and retirement status.

\section{METHODS}

Data

The Whitehall II study is an ongoing longitudinal study of 10308 male and female civil servants (initially aged 35-55) based in London and set up in $1985 .{ }^{16} \mathrm{We}$ analysed the third (1991-3, $\mathrm{n}=8637)$, fourth (1995-6, $\mathrm{n}=8629)$, fifth (1997-9, $\mathrm{n}=7830)$, sixth (2001, $\mathrm{n}=7344)$, and seventh $(2002-4, \mathrm{n}=6914)$ phases of the study.

\section{Variables}

The United Kingdom standard version of the SF-36 questionnaire was administered on five occasions (phases 3 to 7). This is a well validated 36 item questionnaire covering issues relating to physical, psychological, and social functioning. ${ }^{1718}$ The original eight scales of this questionnaire (physical function, role limitations due to physical problems, pain, general health perception, general mental health, role limitations due to emotional problems, energy/vitality, and social functioning) can be summarised into physical and mental health components by a method based on factor analysis. ${ }^{19}$ Each physical and mental health component score ranges from 0 to 100 , with lower scores implying poorer health. In the general population in the United States the mean score is 50 .

Occupational class was measured as the participant's civil service employment grade at each phase, which could vary over time. Participants were also asked at each phase to classify their employment status, with "retired" as an option. Thus employment/retirement status could also vary over time. For example, a participant could report being retired at one phase and in employment at a later phase, although most remained retired after the first report. Age was centred at 56 , the mean age across all phases.

\section{Analysis}

A parsimonious method for the analysis of repeated measures is to estimate the trajectories of the measure (the intercept and slope) as a function of time. A growth curve plots these trajectories as a function of time (age in this study). Use of a quadratic function (age and age ${ }^{2}$ ) in these models allows for non-linear changes so the effect of age on the physical and mental component scores can increase or slow down over time.

Growth curve models of the effects of age plus period, age plus cohort, and cohort plus period can be estimated from longitudinal data with more than two waves of repeated measures. We controlled for period effects by taking account of participation at each phase and estimated Cohort effects by adding in birth year. Only age plus period, age plus cohort, or cohort plus period effects can be estimated at any one time. Preliminary analyses showed the best fitting models
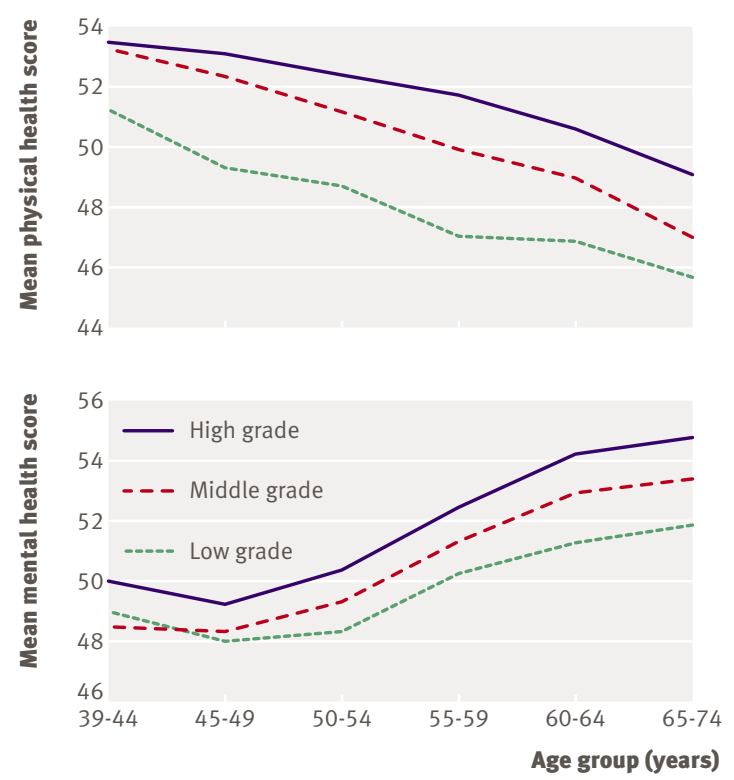

Fig 1 | Mean SF-36 physical component scores and mental component scores by age group: Whitehall II respondents from phases 3-7

included age and period effects, with cohort effects being relatively smaller. Hence we used age and period effects in the growth curve models in this paper and assumed that cohort effects are negligible. ${ }^{11}$

We included sex and retirement status at each phase in the models. Two way interaction terms between time specific employment grade and the age terms estimate whether grade effects on health differ as the cohort gets older. We used this baseline model to examine if health inequalities increased with age. We tested further two way interaction effects between age, sex, and retirement status to examine if the effect of age was modified by sex or retirement (do health trajectories differ by sex or retirement status). Three way interaction effects were examined to see if the occupational class trajectories of health were modified by age or sex. Subgroup analyses run the risk of being underpowered so we performed power calculations by estimating the power required to detect the effect of age on mental and physical component scores in specific subgroups (for women and retired people). For the two way interactions, the power to detect significant effects was over $85 \%$. The power to detect significant effects for some of the three way interactions, however, was as little as $25 \%$.

\section{RESULTS}

Figure 1 shows the mean SF-36 physical and mental component scores for each occupational grade plotted against age. Physical health deteriorated for all occupational groups at older ages, while mental health tended to improve with age. This change in SF-36 scores may be an ageing effect. Alternatively, the change may be caused by cohort effects (the oldest cohort member was born in 1930, the youngest in 1952) or period effects (such as retirement at any of the measurement phases). 
Tables 1 and 2 show the mean SF-36 physical and mental component scores at each phase of data collection by age group, employment grade, retirement status, and sex. The physical component scores for men at phase 3 show that older men have poorer (lower) physical health. Comparing phase 3 with later phases, in each age group men from later phases also have poorer physical health.

We found similar patterns of age and period related declines in physical component scores among women, although the mean levels tended to be lower than in men. In contrast, older men and women have better (higher) mean mental component scores than younger men and women. Furthermore, at later periods there was a small increase in mental health scores for the older age groups (indicating a small improvement in mental health). There was a social gradient in physical health at phase 3 , which tended to widen considerably among women, but less so among men. There was not much of a social gradient in mental health among men and women at phase 3 . By phase 7 , however, people from higher employment grades had better mental health than those from lower grades.

Table 3 shows the estimated coefficients from fitting growth curve models to the data in table 1. For the physical component score in model I, the constant term refers to the mean physical health (52.97) for the reference group: high grade, non-retired men aged 56 in 1991-3. A quadratic growth model (with age and age $^{2}$ terms) was specified with a single year increase in age resulting in poorer physical health (a decrease of 0.03 from age 56 to 57). This negative effect of age on physical health was curtailed as respondents got older, indicated by the positive and significant effect of age ${ }^{2}$. A lower employment grade was associated with poorer physical health; at age 56, the gap between high and low grades was 1.60. Furthermore, the interaction between age and grade was negative; those in the middle grades aged 57 had a lower physical component score $(-0.06)$ than when they were aged 56 . There was a similar effect for the lowest grades $(-0.05)$. This significant interaction term between age and grade indicates that health inequalities increase as this cohort got older. Over 20 years, the gap between high and low grades increased by $1(20 \times-0.05)$. The trajectory of health decline for higher grades is not as steep as for those in middle and lower grades (fig 2).

The mean physical component score for an average high grade retired man aged 70 in 2002-4 can be calculated from model I in table 3 as 47.8. This is around the same mean physical component score for a low grade retired man from the same period aged 62 . Thus, the average physical health of a 70 year old high grade man is similar to a low grade man around 8 years younger.

Table 1 | Mean SF-36 physical component score for Whitehall II participants, 1991-2004, with numbers in cohort shown in brackets

\begin{tabular}{|c|c|c|c|c|c|}
\hline & \multicolumn{5}{|c|}{ Study phase (age range) } \\
\hline & Phase $3\left(39-63^{*}\right)$ & Phase 4 (42-65) & Phase 5 (45-69) & Phase $6(48-71)$ & Phase $7(50-74)$ \\
\hline \multicolumn{6}{|l|}{ Men } \\
\hline \multicolumn{6}{|c|}{ Age (years) at phase 3: } \\
\hline $39-44$ & $53.9(1559)$ & $52.6(1391)$ & $53.0(1285)$ & $52.3(1210)$ & $51.2(1247)$ \\
\hline $45-49$ & $53.6(1596)$ & $52.4(1446)$ & $52.3(1344)$ & $51.7(1250)$ & $50.6(1296)$ \\
\hline $50-54$ & $52.3(1134)$ & $50.9(1042)$ & $51.2(963)$ & $50.6(919)$ & $49.1(918)$ \\
\hline $55-63$ & $51.8(1440)$ & $50.0(1341)$ & $50.6(1237)$ & 49.1 (1186) & 47.8 (1134) \\
\hline \multicolumn{6}{|c|}{ Employment grade: } \\
\hline High & $53.3(2766)$ & $51.9(2688)$ & $52.2(2572)$ & $51.2(2541)$ & $50.2(2604)$ \\
\hline Middle & $52.9(2582)$ & $51.4(2317)$ & $51.5(2089)$ & 50.7 (1909) & 49.2 (1917) \\
\hline Low & $51.0(381)$ & $48.8(325)$ & $50.6(250)$ & $49.3(212)$ & $49.4(173)$ \\
\hline \multicolumn{6}{|c|}{ Retirement status: } \\
\hline Not retired & $53.2(5158)$ & $51.9(4418)$ & $52.3(3559)$ & $51.7(2964)$ & $50.9(2709)$ \\
\hline Retired & $50.6(563)$ & $49.6(912)$ & $50.6(1348)$ & $49.5(1698)$ & $48.2(1985)$ \\
\hline \multicolumn{6}{|l|}{ Women } \\
\hline \multicolumn{6}{|c|}{ Age at phase 3: } \\
\hline $39-44$ & $52.2(577)$ & $51.0(514)$ & $51.0(471)$ & $51.0(449)$ & $49.5(454)$ \\
\hline $45-49$ & $49.9(635)$ & $48.7(570)$ & $49.0(519)$ & $47.8(466)$ & $46.6(489)$ \\
\hline $50-54$ & $49.4(554)$ & $47.7(459)$ & $47.3(419)$ & $48.0(392)$ & $46.2(390)$ \\
\hline $55-63$ & $48.4(797)$ & $47.2(719)$ & $46.9(567)$ & $45.4(593)$ & $43.1(542)$ \\
\hline \multicolumn{6}{|c|}{ Employment grade: } \\
\hline High & $52.0(403)$ & $50.7(407)$ & $50.9(406)$ & $50.3(440)$ & $48.8(440)$ \\
\hline Middle & $50.2(1155)$ & $48.9(1063)$ & 48.4 (951) & $47.8(976)$ & $46.2(963)$ \\
\hline Low & $48.7(1005)$ & $46.9(870)$ & $47.2(660)$ & $45.5(524)$ & $43.5(519)$ \\
\hline \multicolumn{6}{|c|}{ Retirement status: } \\
\hline Not retired & $50.6(2292)$ & $49.1(1785)$ & 49.2 (1373) & $49.1(1032)$ & $47.9(936)$ \\
\hline Retired & $43.9(271)$ & $46.3(555)$ & $46.9(642)$ & $46.2(908)$ & $44.4(986)$ \\
\hline
\end{tabular}

*In women the age range for phase 3 was 39-64. 
There was a similar 8 year gap between high and low grades among women. In comparison, a high grade man aged 45 in 1991-2 had an estimated physical component score of 53.8, which is around the same as for a low grade man who was 4.5 years younger. So the age gap in physical health between employment grades widens from 4.5 to 8 years from mid-life to early old age.

Model II adjusts for confounders that could explain the widening health inequalities with age- -namely, the interaction effects between grade, sex, and retirement (table 3). We included only significant interaction effects in the model. Neither sex nor retirement modified the effect of age, indicating that the trajectories of physical health did not differ by sex or retirement status. Women from lower grades reported poorer physical health than men from similar grades. Retired women also reported poorer physical health than retired men. The effect of retirement on physical health differed by grade, with retirement being associated with less of a decline in physical health for low grades compared to high grades. Despite the inclusion of these significant interaction terms, the interaction effect between grade and age did not change much compared with model I, indicating that the widening gap in health inequalities with age was not explained by the inclusion of these other interaction effects in the model.

\section{Table 2 | Mean SF-36 mental component score for Whitehall II participants, 1991-2004, with numbers in cohort shown in brackets}

Study phase (age range)

\begin{tabular}{lcccc}
\hline & Phase 4 (42- & Phase 5 (45- & Phase 6 (48- & \\
Phase 3 $\left(39-63^{\star}\right)$ & $65)$ & $69)$ & $71)$ & Phase 7 (50-74)
\end{tabular}

Men

Age (years) at phase 3 :

\begin{tabular}{|c|c|c|c|c|c|}
\hline $39-44$ & 49.9 (1559) & $47.9(1391)$ & $48.6(1285)$ & $49.1(1210)$ & $49.7(1247)$ \\
\hline $45-49$ & $50.6(1596)$ & $49.5(1446)$ & $51.0(1344)$ & $51.6(1250)$ & 52.4 (1296) \\
\hline 50-54 & 51.9 (1134) & $51.2(1042)$ & $52.6(963)$ & 53.7 (919) & $54.2(918)$ \\
\hline $55-59$ & $53.5(1440$ & 53.7 (1341) & $54.1(1237)$ & $53.9(1186)$ & 54.4 (1134) \\
\hline \multicolumn{6}{|c|}{ Employment grade: } \\
\hline High & $51.7(2766)$ & $51.3(2688)$ & $52.2(2572)$ & $52.6(2541)$ & $52.8(2604)$ \\
\hline Middle & $51.1(2582)$ & $49.9(2317)$ & $51.0(2089)$ & 51.5 (1909) & $52.3(1917)$ \\
\hline Low & $51.3(381)$ & $47.8(325)$ & $48.5(250)$ & $48.1(212)$ & 49.9 (173) \\
\hline \multicolumn{6}{|c|}{ Retirement status: } \\
\hline Not retired & $51.2(5158)$ & $49.6(4418)$ & $50.5(3559)$ & $51.1(2964)$ & $51.3(2709)$ \\
\hline Retired & $53.6(563)$ & $54.5(912)$ & $54.0(1348)$ & $53.4(1698)$ & $54.2(19850$ \\
\hline \multicolumn{6}{|l|}{ Women } \\
\hline \multicolumn{6}{|c|}{ Age (years) at phase 3: } \\
\hline $39-44$ & $48.0(577)$ & $47.3(514)$ & $46.6(471)$ & 47.9 (449) & $49.1(454)$ \\
\hline $45-49$ & $49.1(635)$ & $47.6(570)$ & $48.6(519)$ & $49.9(466)$ & $50.6(489)$ \\
\hline 50-54 & $50.5(554)$ & $49.1(459)$ & $50.5(419)$ & 51.9 (392) & $52.5(390)$ \\
\hline $55-59$ & $52.5(797)$ & $51.8(719)$ & $52.7(567)$ & $52.2(593)$ & $53.0(542)$ \\
\hline \multicolumn{6}{|c|}{ Employment grade: } \\
\hline High & $49.6(403)$ & $49.4(407)$ & $50.0(406)$ & $50.8(440)$ & $52.1(440)$ \\
\hline Middle & $49.8(1155)$ & $48.5(1063)$ & $49.2(951)$ & $50.5(976)$ & $50.8(963)$ \\
\hline Low & $51.0(1005)$ & $49.6(870)$ & $50.2(660)$ & $50.3(524)$ & $51.7(519)$ \\
\hline \multicolumn{6}{|c|}{ Retirement status: } \\
\hline Not retired & $50.1(2292)$ & $48.3(1785)$ & 48.7 (1373) & $49.3(1032)$ & $49.8(936)$ \\
\hline Retired & $51.1(271)$ & $51.6(555)$ & $51.8(642)$ & 51.9 (908) & $52.8(986)$ \\
\hline
\end{tabular}

*In women the age range for phase 3 was 39-64.
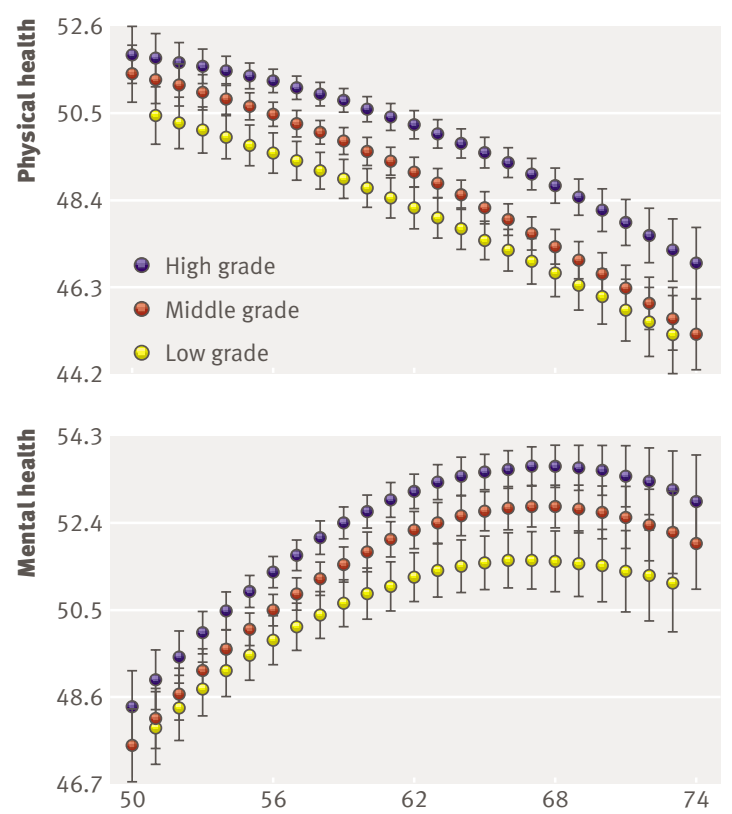

Age (years)

Fig 2 | Trajectories of age related increase in SF-36 physical component and mental component scores by employment grade; Whitehall II phase 7 (estimated from model I, table 3)

For the mental component scores in model I (table 3), the constant refers to the mean mental health (52.22) for the reference group: high grade, non-retired men aged 56 in 1991-3. Ageing by one year was associated with better mental health (an increase of 0.16 in mental component score). A lower employment grade was associated with poorer mental health. Furthermore, the interaction between age and low grade was negative. Low grade men and women aged 57 years had a mental component score 0.07 lower than when they were 56 years old, indicating health inequalities increased with age. Figure 2 shows this for the latest period. At age 50, there was little social inequality in mental health, but a gap opened up as the cohort got older, with low grade older people not attaining the same high mental health as high grade older people.

In model II, neither sex nor retirement modified the effect of age, indicating that the trajectories of mental health did not differ by sex or retirement status. Women from the lowest grades reported better mental health than men from the same grade. Retirement for lower grades was associated with poorer mental health than in those in high grades. The interaction between low grade and age reduced significantly (from -0.07 to nearly zero), indicating that the widening gap in mental health inequalities with age was explained by the inclusion of the other interaction effects. The interaction between grade and retirement, in particular, explained most of the interaction between grade and age, suggesting that the widening gap in mental health with age is mainly because of the increase in mental component scores among the retired high grades. 


\section{DISCUSSION}

Widening inequalities with age

The trajectories for physical health differ between occupational grades. We found that a 70 year old person who worked in a high grade civil service job had similar physical health to a 62 year old person from the lowest grade. This gap was smaller in mid-life. People from lower occupational grades seem to age faster in terms of declines in physical health than those from higher grades. This results in a widening gap in health inequalities as people enter early old age. We found no significant differences in these trajectories by sex and retirement status, although women from lower grades and retired women reported poorer physical health than men from the same grades and retirement status.
Mental health seems to improve with age for all occupational groups, although this improvement is slower for lower occupational grades, resulting in widening health inequalities in early old age. This widening gap was not a result of differing trajectories by sex or retirement status. Rather it was explained by the better mental health attained by the higher occupational grades after retirement. Retirement was not associated with a similar improvement in mental health for the lower grades. Other studies that have found positive effects of retirement on mental health may not have been able to investigate such interactions between social class and retirement. ${ }^{2021}$

Inequalities in self reported health increased from mid-life to early old age in a cohort aged 39-63 at

Table 3 | Estimates (standard errors) of physical and mental functioning and growth curve models fitted to Whitehall II men and women: full model

\begin{tabular}{|c|c|c|c|c|}
\hline \multirow[b]{2}{*}{ Fixed effects } & \multicolumn{2}{|c|}{ Physical component scores } & \multicolumn{2}{|c|}{ Mental component scores } \\
\hline & Model I* & Model II† & Model I* & Model II† \\
\hline Constant & $52.97(0.14)$ & $52.98(0.15)$ & $52.22(0.16)$ & $52.09(0.17)$ \\
\hline Current age (mean centred at age 56) & $-0.03(0.01)$ & $-0.01(0.01)$ & $0.16(0.02)$ & $0.13(0.02)$ \\
\hline $\mathrm{Age}^{2}$ & $0.004(0.001)$ & $0.003(0.001)$ & $0.003(0.001)$ & $0.002(0.001)$ \\
\hline \multicolumn{5}{|l|}{ Period: } \\
\hline $1991-3$ & 0 & 0 & 0 & 0 \\
\hline $1995-6$ & $-1.55(0.13)$ & $-1.56(0.13)$ & $-0.85(0.15)$ & $-0.83(0.15)$ \\
\hline $1997-9$ & $-1.07(0.14)$ & $-1.09(0.14)$ & $-0.44(0.17)$ & $-0.45(0.17)$ \\
\hline 2001 & $-1.01(0.15)$ & $-1.04(0.15)$ & $0.68(0.17)$ & $-0.63(0.17)$ \\
\hline $2002-4$ & $-1.74(0.16)$ & $-1.78(0.16)$ & $-0.84(0.18)$ & $-0.78(0.18)$ \\
\hline \multicolumn{5}{|c|}{ Employment grade (non-retired men aged 56 in 1991-3): } \\
\hline High grade & 0 & 0 & 0 & 0 \\
\hline Middle grade & $-0.78(0.13)$ & $-0.79(0.16)$ & $-0.86(0.15)$ & $-0.70(0.18)$ \\
\hline Low grade & $-1.60(0.20)$ & $-1.48(0.31)$ & $-1.35(0.22)$ & $-1.81(0.35)$ \\
\hline \multicolumn{5}{|l|}{ Sex (high grade, not retired in 1991-3): } \\
\hline Men & 0 & 0 & 0 & 0 \\
\hline Women & $-2.65(0.17)$ & $-1.96(0.29)$ & $-1.19(0.18)$ & $-1.56(0.32)$ \\
\hline \multicolumn{5}{|c|}{ Retirement status (high grade men aged 56 in 1991-3): } \\
\hline Not retired & 0 & 0 & 0 & 0 \\
\hline Retired & $-0.54(0.11)$ & $-0.80(0.16)$ & $1.17(0.12)$ & $1.72(0.19)$ \\
\hline \multicolumn{5}{|c|}{ Interactions (reference group high grade, non-retired men aged 56 in 1991-3) } \\
\hline \multicolumn{5}{|l|}{ Agexperiod: } \\
\hline $1995-6$ & $-0.07(0.02)$ & $-0.07(0.02)$ & $0.13(0.02)$ & $0.14(0.02)$ \\
\hline $1997-9$ & $-0.09(0.02)$ & $-0.09(0.02)$ & $0.12(0.02)$ & $0.13(0.02)$ \\
\hline 2001 & $-0.10(0.03)$ & $-0.01(0.03)$ & $0.17(0.03)$ & $0.17(0.03)$ \\
\hline $2002-4$ & $-0.11(0.04)$ & $-0.11(0.04)$ & $0.23(0.04)$ & $0.24(0.04)$ \\
\hline \multicolumn{5}{|l|}{ Age $^{2} \times$ period: } \\
\hline $1995-6$ & $-0.001(0.002)$ & $-0.001(0.002)$ & $0.003(0.003)$ & $0.003(0.003)$ \\
\hline $1997-9$ & $0.003(0.003)$ & $0.002(0.003)$ & $-0.013(0.003)$ & $-0.012(0.003)$ \\
\hline 2001 & $-0.006(0.003)$ & $-0.006(0.003)$ & $-0.019(0.003)$ & $-0.018(0.003)$ \\
\hline $2002-4$ & $-0.009(0.003)$ & $-0.009(0.003)$ & $-0.019(0.003)$ & $-0.019(0.003)$ \\
\hline Agexmiddle grade & $-0.06(0.01)$ & $-0.07(0.01)$ & $0.00(0.01)$ & $0.02(0.02)$ \\
\hline Agexlow grade & $-0.05(0.02)$ & $-0.07(0.02)$ & $-0.07(0.02)$ & $0.00(0.02)$ \\
\hline Middle grade women & - & $-0.80(0.33)$ & - & $0.06(0.37)$ \\
\hline Low grade women & - & $-0.90(0.44)$ & - & $1.77(0.49)$ \\
\hline Middle grade retired & - & $0.68(0.22)$ & - & $-0.54(0.26)$ \\
\hline Low grade retired & - & $0.70(0.33)$ & - & $-2.60(0.38)$ \\
\hline Retired women & - & $-0.40(0.21)$ & - & $0.20(0.25)$ \\
\hline
\end{tabular}

*Adjusts for age, period, employment grade, sex, and retirement effects, and interaction effects between agexperiod, and agexemployment grade. †Additionally adjusts for interaction effects between employment gradexsex, employment gradexretirement, and retirement×sex. 


\section{WHAT IS ALREADY KNOWN ON THIS TOPIC}

Although absolute differences in health between socioeconomic groups increase in older age groups, there is some debate about whether relative health inequalities converge, persist, or increase in later life

\section{WHAT THIS STUDY ADDS}

Relative social inequalities in physical and mental health increase between middle age and early old age

Occupational class continues to affect the self reported health of older people well into their retirement

People from lower occupational grades age faster in terms of a quicker decline in physical health than people from higher grades
In the Whitehall II study, relative differences between occupational grades in self rated health tend to be similar to those seen with more objective measures like ischaemia confirmed by electrocardiography. ${ }^{22}$

Social inequalities in reported health increase from mid-life to early old age. Occupational class continues to affect the health and functioning of older people well into their retirement. A 70 year old retired person from the highest civil service grade has similar physical health, on average, to a lower grade person eight years younger. For mental health, retirement is associated with better mental health only for those in high grades. These results suggest that ageing in later life is not necessarily accompanied by steep decrements in health. Despite greater need, elderly people from disadvantaged social classes face barriers in accessing health services. ${ }^{23}$ Helping people from disadvantaged social classes to achieve the good health that is attained by more advantaged groups would help to reduce need and prevent the growing crisis in healthcare inequalities among elderly people as the population ages.

We thank all participating civil service departments and their welfare, personnel, and establishment officers; the Occupational Health and Safety Agency; the Council of Civil Service Unions; all participating civil servants in the Whitehall II study; and all members of the Whitehall II study team. In addition, we thank Pau Clarke for his invaluable statistical advice.

Contributors: TC wrote the first draft, did the analysis, and is guarantor. JF, AS, and $\mathrm{MM}$ contributed to subsequent drafts of the paper by writing sections and suggesting new analytical strategies.

Funding: The Whitehall II study has been supported by grants from the Medical Research Council; Economic and Social Research Council; British Hear Foundation; Health and Safety Executive; Department of Health; National Heart Lung and Blood Institute (HL36310) and National Institute on Aging (AG13196) Agency for Health Care Policy Research (HS06516); and the John D and Catherine T MacArthur Foundation Research Networks on Successful Midlife Development and Socio-economic Status and Health. MM is supported by an MRC research professorship.

Competing interests: None declared.

Ethical approval: University College London Medical School committee on the ethics of human research.

1 Marmot M, Banks J, Blundell R, Lessof C, Nazroo J. Health, wealth and lifestyles of the older population in England: the 2002 English longitudinal study of ageing. London: Institute for Fiscal Studies, 2002.

\section{Limitations}

A potential limitation is the nature of the cohort, which comprised mainly white collar, office based civil servants, thus limiting inferences about the general working population. If health inequalities increase in early old age within a cohort of civil servants, however, it is highly likely that they will also increase in a more general population containing greater numbers of people from routine and manual occupations. Another potential limitation of the analyses is selective dropout from the cohort. Those from lower grades are more likely to drop out or have missing data at later periods. This has the potential to result in further underestimation of our observed inequalities in health and also result in low power to detect significant three way interaction effects on whether the occupational grade trajectories of health differ by sex or retirement status. Finally, self reported measures of health are subject to biases that may underestimate or overestimate health inequalities.
2 Marmot MG, Shipley MJ. Do socioeconomic differences in mortality persist after retirement? 25 year follow up of civil servants from the first Whitehall study. BMJ 1996;313:1177-80.

3 Huisman M, Kunst AE, Mackenbach JP. Socioeconomic inequalities in morbidity among the elderly; a European overview. Soc Sci Med 2003;57:861-73.

4 Von Dem KO, Luschen G, Cockerham WC, Siegrist J. Socioeconomic status and health among the aged in the United States and Germany: a comparative cross-sectional study. Soc Sci Med 2003;57:1643-52.

5 House JS, Lepkowski JM, Kinney AM, Mero RP, Kessler RC, Herzog AR. The social stratification of aging and health. J Health Soc Behav 1994;35:213-34.

6 Beckett M. Converging health inequalities in later life-an artifact of mortality selection. J Health Soc Behav 2000;41:106-19.

7 Liang J, Bennett J, Krause N, Kobayashi E, Kim H, Brown JW, et al. Old age mortality in Japan: does the socioeconomic gradient interact with gender and age? J Gerontol B Psychol Sci Soc Sci 2002;57:S294-307.

8 Ross CE, Wu CL. Education, age, and the cumulative advantage in health. J Health Soc Behav 1996;37:104-20.

9 Ferraro KF, Farmer MM. Double jeopardy to health hypothesis for African Americans: analysis and critique. J Health Soc Behav 1996;37:27-43.

10 Hoffman R. Do socioeconomic mortality differences decrease with rising age? Demogr Res 2005;13:35-62.

11 Sacker A, Clarke P, Wiggins RD, Bartley M. Social dynamics of health inequalities: a growth curve analysis of aging and self assessed 
health in the British household panel survey 1991-2001. J Epidemiol Community Health 2005;59:495-501.

12 Yang Y. Age, Period, Cohort Distinctions. Encyclopedia of health and aging. Thousand Oaks, CA: Sage Publications, 2006.

13 Macintyre S, Hunt K, Sweeting H. Gender differences in health: are things really as simple as they seem? Soc Sci Med 1996;42:617-24.

14 Arber S, Cooper H. Gender differences in health in later life: the new paradox? Soc Sci Med 1999;48:61-76

15 Mein G, Martikainen P, Stansfeld SA, Brunner EJ, Fuhrer R, Marmot MG. Predictors of early retirement in British civil servants. Age Ageing 2000;29:529-36.

16 Marmot M, Brunner E. Cohort profile: the Whitehall II study. Int Epidemiol 2005;34:251-6.

17 Ware JE Jr, Sherbourne CD. The MOS 36-item short-form health survey (SF-36). I. Conceptual framework and item selection. Med Care 1992;30:473-83.

18 Hemingway H, Stafford M, Stansfeld S, Shipley M, Marmot M. Is the SF-36 a valid measure of change in population health? Results from the Whitehall II Study. BMJ 1997;315:1273-9.
19 Ware JE, Kosinski M, Keller SD. SF-36 physical and mental health summary scales: a user manual. Massachusetts: Health Institute, New England Medical Center, 1994.

20 Drentea P. Retirement and mental health. J Aging Health 2002;14:167-94.

21 Midanik LT, Soghikian K, Ransom LJ, Tekawa IS. The effect of retirement on mental health and health behaviors: the Kaiser Permanente retirement study. J Gerontol B Psychol Sci Soc Sci 1995;50:S59-61.

22 Marmot MG, Smith GD, Stansfeld S, Patel C, North F, Head J, et al. Health inequalities among British civil servants: the Whitehall I study. Lancet 1991;337:1387-93.

23 Allin S, Masseria C, Mossialos E. Inequality in health care use among older people in the United Kingdom: an analysis of panel data. London: LSE Health, London School of Economics and Politica Science, 2006. (Working Paper No 1/2006.)

Accepted: 15 February 2007 